Supporting Information for:

\title{
A Modified Method for Measuring the Solubility of Pharmaceutical Compounds in Organic Solvents by Visual Camera
}

Ning Tang, Wei Shi, and Weidong Yan

Department of Chemistry, Zhejiang University, Hangzhou 310027, China 
Figure S1. The ${ }^{1} \mathrm{H}$ NMR spectrum of betulonic acid

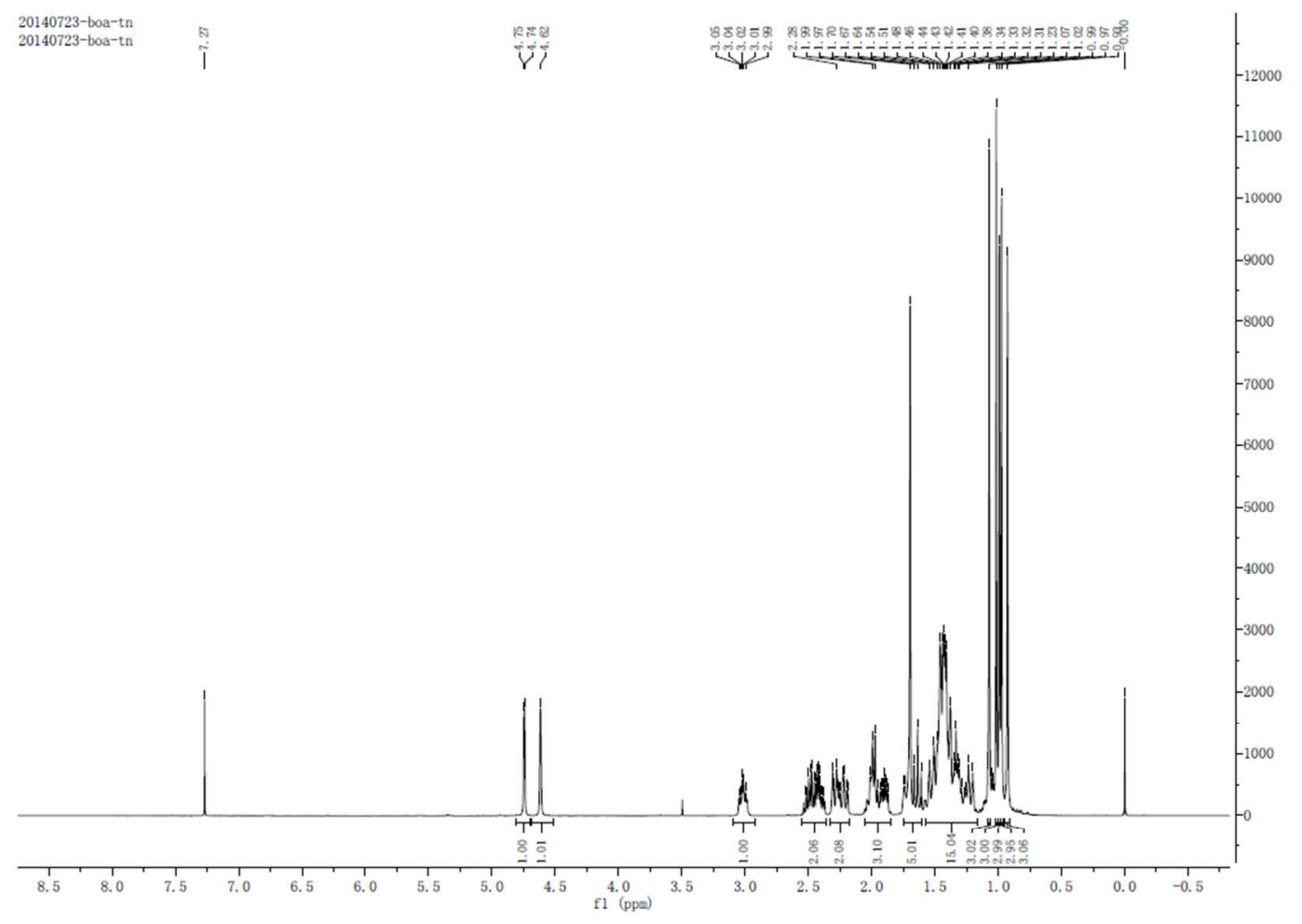

1H NMR (400 MHz, CDCl3) $\delta 4.74(\mathrm{~d}, \mathrm{~J}=1.7 \mathrm{~Hz}, 1 \mathrm{H}), 4.62(\mathrm{~s}, 1 \mathrm{H}), 3.10-2.92(\mathrm{~m}$, 1H), $2.55-2.36(\mathrm{~m}, 2 \mathrm{H}), 2.33-2.17(\mathrm{~m}, 2 \mathrm{H}), 2.05-1.85(\mathrm{~m}, 3 \mathrm{H}), 1.75-1.60(\mathrm{~m}, 5 \mathrm{H})$, $1.57-1.16(\mathrm{~m}, 15 \mathrm{H}), 1.07(\mathrm{~s}, 3 \mathrm{H}), 1.02(\mathrm{~s}, 3 \mathrm{H}), 0.99(\mathrm{~s}, 3 \mathrm{H}), 0.97(\mathrm{~s}, 3 \mathrm{H}), 0.93(\mathrm{~s}, 3 \mathrm{H})$. 
Figure S2. The ${ }^{13} \mathrm{C}$ NMR spectrum of betulonic acid

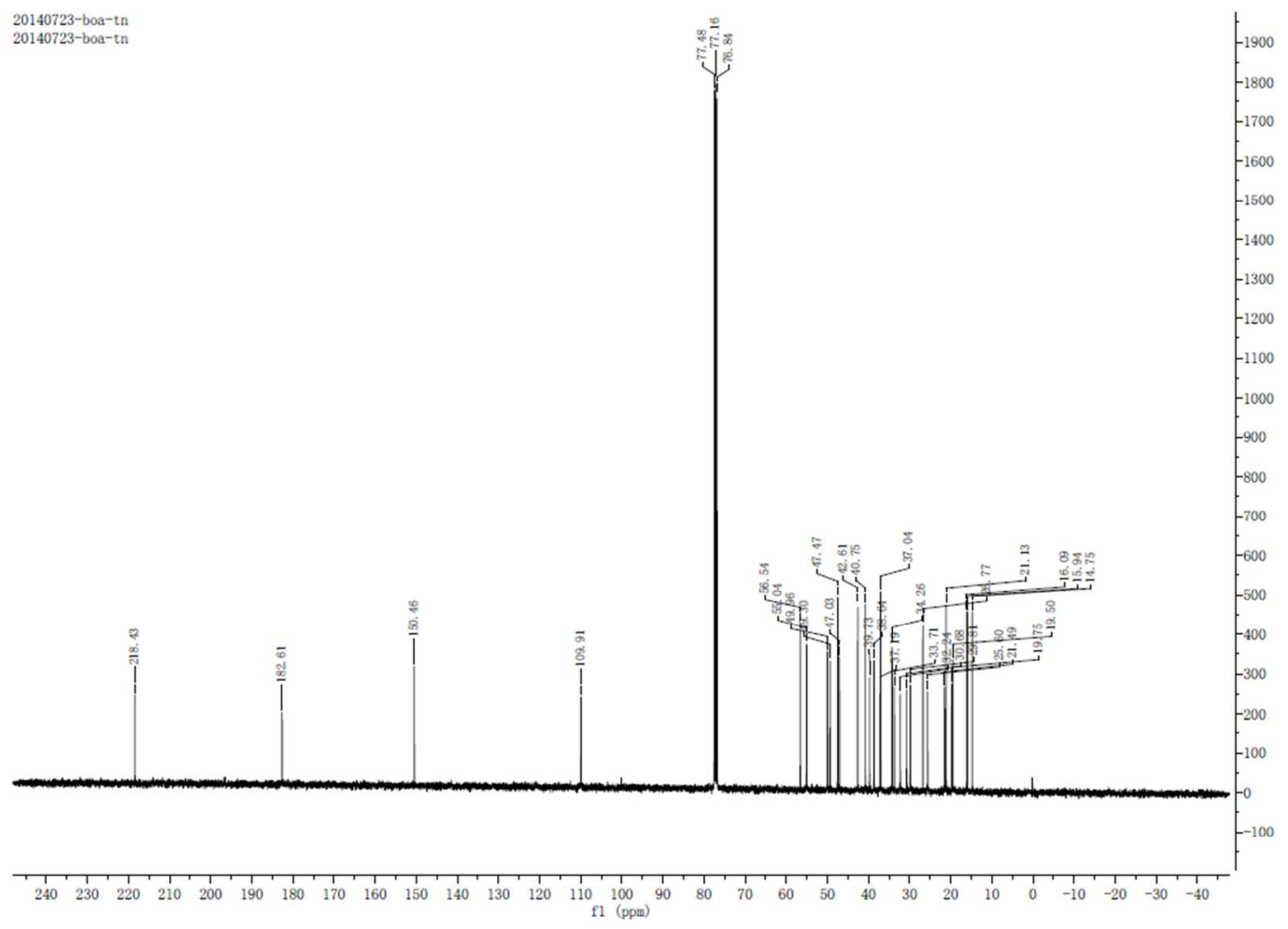

13C NMR (101 MHz, CDC13) $\delta 218.43,182.61,150.46,109.91,56.54,55.04,49.96$, $49.30,47.47,47.03,42.61,40.75,39.73,38.64,37.19,37.04,34.26,33.71,32.24,30.68$, $29.81,26.77,25.60,21.49,21.13,19.75,19.50,16.09,15.94,14.75$. 
Table S1. The Solubility $S$ (g/100g of Solvent) and Relative Error $E_{\mathrm{r}}$ of $\mathrm{NH}_{4} \mathrm{Cl}$ Compared with Literature Value at Temperature $T=283.2 \mathrm{~K}, 293.2 \mathrm{~K}$ and $303.2 \mathrm{~K}$ and Pressure $p=0.1 \mathrm{MPa}^{a}$

\begin{tabular}{|c|c|c|c|}
\hline$T / K$ & $S /(\mathrm{g} / 100 \mathrm{~g})$ & $S /(\mathrm{g} / 100 \mathrm{~g})^{b}$ & $E_{r} \%$ \\
\hline 283.2 & 33.56 & 33.3 & 0.78 \\
\hline 293.2 & 37.29 & 37.2 & 0.24 \\
\hline 303.2 & 41.14 & 41.4 & 0.63 \\
\hline \multicolumn{4}{|c|}{${ }^{a}$ Standard uncertainties $u$ are $u(T)=0.01 \mathrm{~K}, u(p)=5 \mathrm{Kpa}, u_{\mathrm{r}}(S)=0.03$; } \\
\hline \multicolumn{3}{|c|}{$\begin{array}{l}{ }^{b} \text { Cohen-Adad, R. and Lorimer, J . W. (Eds.) ( } 1991 \text { ). Solubility data series [Pergamon } \\
\text { Oxford] 47, 413. }\end{array}$} & Press, \\
\hline
\end{tabular}

